\title{
MULTI-AGENT BASED SIMULATION OF OPTIMAL URBAN LAND USE ALLOCATION IN THE MIDDLE REACHES OF THE YANGTZE RIVER, CHINA
}

\author{
Y. Zeng a, b*, W. Huang ${ }^{c}$, W. Jin ${ }^{\text {a, b }}$, S. Li ${ }^{c}$ \\ ${ }^{a}$ School of Geosciences and Info-physics, Central South University, Changsha, 410083, China - ynzeng@ @su.edu.cn \\ ${ }^{\mathrm{b}}$ Center for Geomatics and Sustainabal Development Research, Central South University, Changsha, 410083, China \\ c Department of Civil Engineering, Ryerson University, Toronto, Ontario Canada M5B 2K3 - (wei1.huang, snli)@ ryerson.ca
}

\section{Commission VIII, WG VIII/8}

KEY WORDS: Multi-agent, Simulation, Optimization allocation, Urban, Land use, Chang-Zhu-Tan agglomeration, Central China

\begin{abstract}
:
The optimization of land-use allocation is one of important approaches to achieve regional sustainable development. This study selects Chang-Zhu-Tan agglomeration as study area and proposed a new land use optimization allocation model. Using multi-agent based simulation model, the future urban land use optimization allocation was simulated in 2020 and 2030 under three different scenarios. This kind of quantitative information about urban land use optimization allocation and urban expansions in future would be of great interest to urban planning, water and land resource management, and climate change research.
\end{abstract}

\section{INTRODUCTION}

As the economic development policies are continuously being implemented in China, urban agglomeration as the core area of socio-economic development will be given the priority for rapid development. However, fast urbanization and accelerated urban expansion will convert natural landscape to largely impervious land use patterns. Urban land use and related environmental changes would have impacts on regional sustainable development (Jiang et al., 2013; Lin et al., 2003; Seto et al., 2005; Liu et al., 2008). Therefore, it is important to optimize future urban land use allocation in urban agglomerations.

Optimization of land use allocation is a complex spatial optimization problem that involves allocating various land uses to specific units within a region. Therefore, a number of models have been widely used to simulate land use transformation. They include mathematical equation and empirical statistical model (Haque et al., 2014), intelligent evolutionary algorithm (Liu et al., 2012; 2013) and CLUE-S model (Verburg et al., 1999; 2002), CA model (Li et al., 2002; He et al., 2006), among which Cellular Automata (CA) model has been increasingly used to simulate urban growth and land use dynamics. However, the simulation of multiple land use changes using CA models is difficult because numerous spatial variables and parameters have to be utilized. They also have some limitations because they cannot explicitly consider the influences of social and human factors in urban expansion simulation.

Multi-agent systems (MAS) can be defined as a set of agents interacting in a common environment, able to modify themselves and their environment. It can explicitly formalize simple to complex representations of the behavior and cognitive processes of actors who make land use decisions within the system. Therefore, Multi-agent systems (MAS) based model is well adapted to the simulation the multiple land use changes in urban areas (An, 2012; Chen et al., 2010).

* Corresponding author
This study selected the Chang-Zhu-Tan agglomeration as study area, which is located in the middle reaches of the Yangtze River and is one of important urban agglomeration areas in China. Based on multi-agent system theory and land use decisionmaking process, a new land use optimization allocation model was developed. Using this multi-agent based simulation model, the future urban land use optimization allocations under three different scenarios were simulated in 2020, 2025 and 2030.

\section{STUDY AREA AND DATA}

The Chang-Zhu-Tan agglomeration in the middle reaches of the Yangtze River, China (Fig. 1) has been experiencing significant growth in both population size and urban area in the last decade. It is important to quantitatively reveal urban expansion in future.

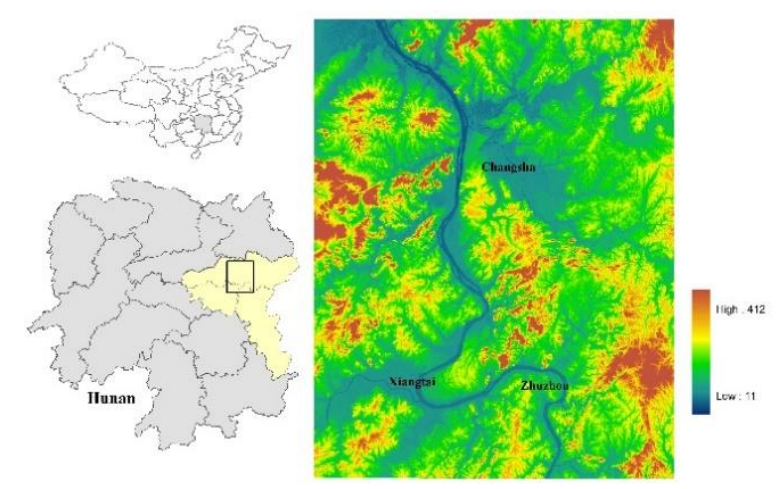

Figure 1. Study area

Land use/cover data were excavated using Landsat TM/OLI images from 2010 to 2013. Land use types include construction land, arable land, forest land, water, and other land use. The overall accuracy of classification of land use/cover data reached $80 \%$. We also collected DEM, topographical map, house price 
map, and socio-economic census data including population density, GDP per capita, urbanization, and total fixed assets.

Using GIS spatial analysis model, we calculated and obtained thematic layers such as, distance to the river, distance to village road, distance to county road, distance to road, distance to highway, distance to bridge, life service, facilitate of work, leisure and entertainment layers.

\section{MULTI-AGENT BASED SPATIAL OPTIMIZATION MODEL}

\subsection{Model framework}

The land use decision-making stakeholders are divided into three categories, such as government, departments, and public, which are macro-level decision maker, land administration decision maker and land users, respectively.

Firstly, the spatial competition allocations of different land use classes are determined through multi-agent based interactive decision-making. Then, under different land use scenarios, the optimized land use allocations are determined according to the configuration order of land use class and the land use structure constraints (Fig. 2).

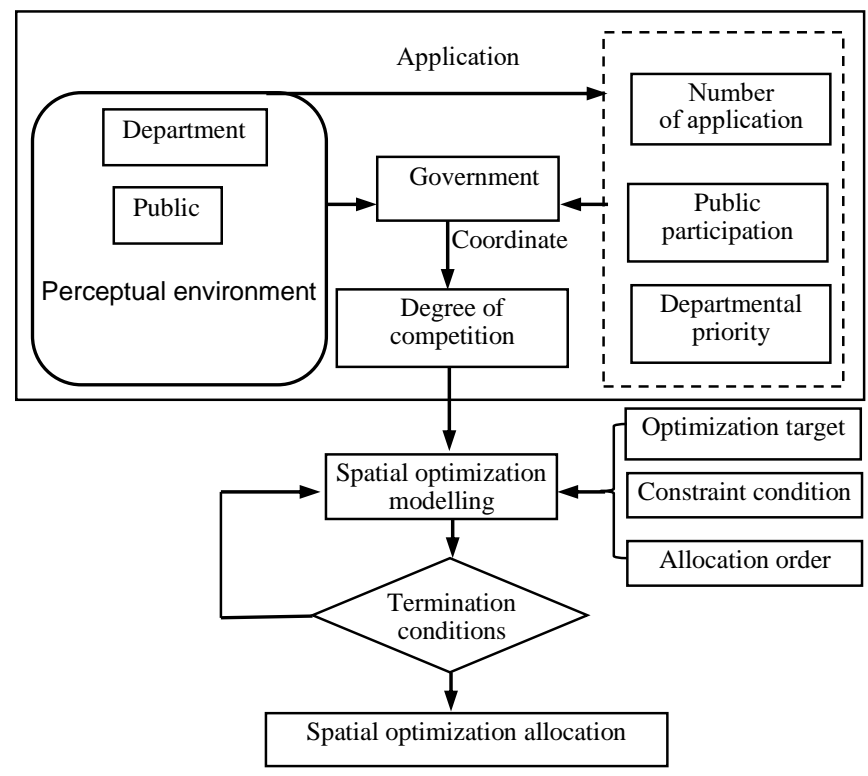

Figure 2. Model framework of multi-agent spatial optimization

\subsection{Multi-agents and their interactive decision making}

(1) Department and public agents and their land use decisions

Department and public agents are pursuing to maximize their own interests. Therefore, based on comprehensive trade-offs of land use effectiveness, department and public agents apply to government for land use. The utility functions of department and public agents for land use are as follows:

$$
U_{i}=\sum_{j=1}^{k} \alpha_{j} X_{j}+\mu_{i j}
$$

$U_{i}$ is the utility of the land use $i ; X_{j}$ is the decision factor of department and public agents $(j=1,2,3 \ldots \mathrm{k})$; $a_{j}$ is the decision weight; $\mu_{\mathrm{ij}}$ is the random disturbance term.

\section{(2) Government agent and its land use decisions}

The government agents use competition function to resolve land use conflicts. The competition function is as follows:

$$
C_{t(i, j)}=U_{d(i, j, t)}+\alpha \cdot U_{p(i, j, t)}+P_{t}
$$

$C_{t(i, j)}$ is the competition of land use class $t$ in unit $(i, j) ; U_{d(i, j, t)}$ and $U_{p(i, j, t)}$ are utility functions of land use class $t$ in unit $(i, j)$ for department and public agents, respectively; $\alpha$ is the public agent participation $(0 \leq \alpha \leq 1) ; \mathrm{P}_{\mathrm{t}}$ is priority of department agent to land use class $\mathrm{t} \quad\left(\mathrm{p}_{\mathrm{t}} \geq 0\right)$.

In order to consider the land requirements of department agent and public agent, the government needs to coordinate land use through competition adjustment as follows:

$$
C_{t(i, j)}^{\prime}=C_{t(i, j)}+n_{d} \cdot \delta P_{d}+n_{p} \cdot \delta P_{p}
$$

$\mathrm{C}^{\prime}{ }_{\mathrm{t}(\mathrm{i}, \mathrm{j})}$ is the adjusted competition for land use class $t$ in unit $(\mathrm{i}, \mathrm{j})$; $\mathrm{n}_{\mathrm{d}}$ and $\mathrm{n}_{\mathrm{P}}$ are number of application of department and public agents to the government for the unit $(\mathrm{i}, \mathrm{j}) ; \delta \mathrm{P}_{\mathrm{d}}$ and $\delta \mathrm{P}_{\mathrm{p}}$ is the competition increase of departments and the public agent for each time.

(3) Land use optimal allocation based on the degree of land use competition

In multi-agent based interactive decision-making process, the optimal allocation of land use was implemented dynamically based on the degree of competition of all land use types, as well as the sequence of configurations of land use and the constraint condition of land use structure.

\section{THE RESULTS AND ANALYSIS}

\subsection{Model test}

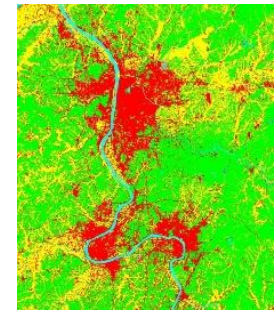

(a)

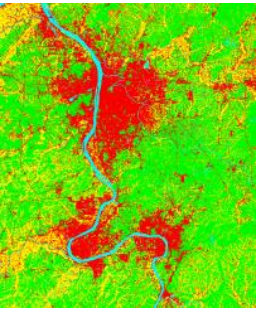

(b)

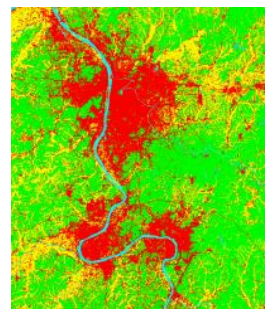

(c)
Constriction land water arable land other land use
Figure 3. Comparison of modelled land use with actual land use: (a) 2010 actual land use, (b) 2013 actual land use, and (c) 2013 modelling result

Based on the land use classification data in 2010, which is the base year data, the spatial pattern of land use in 2013 was simulated by using the multi-agent land use spatial optimization model (see Fig. 3c). Using a cell-by-cell method, we compare the simulated results with the actual land use pattern in 2013 (see 
Fig. 3b). The Kappa coefficient is 0.7716 . This indicated that the modelling accuracy using the multi-agent land use spatial optimization model is sufficient to model the land use allocation.

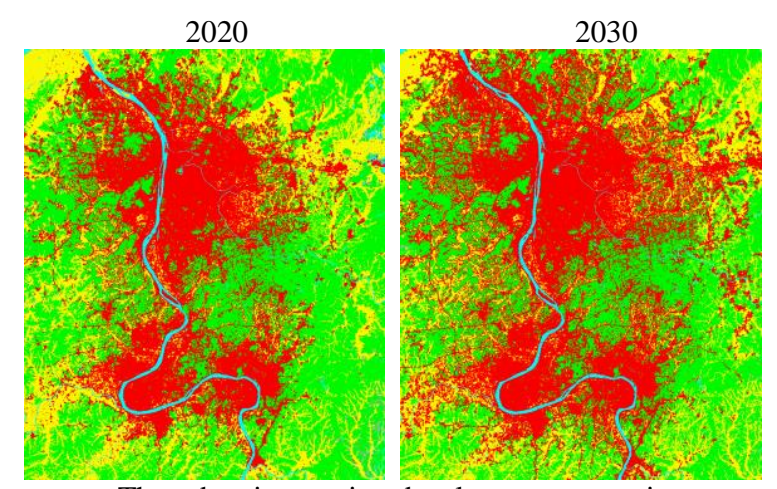

The urban integration development scenario

2020

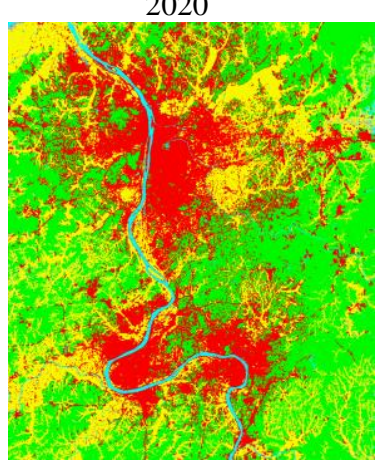

The farmland protection scenario

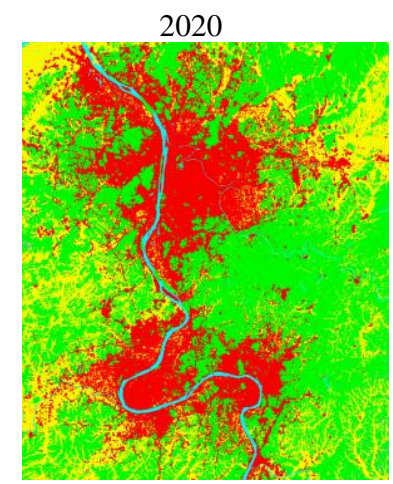

The ecological protection scenario

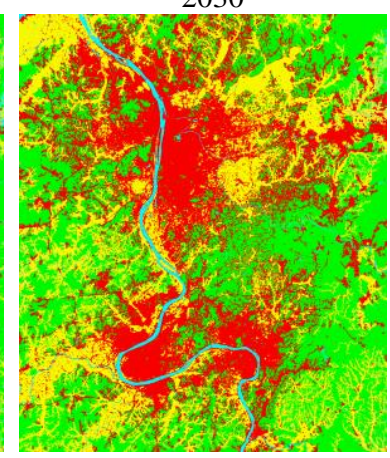

2030

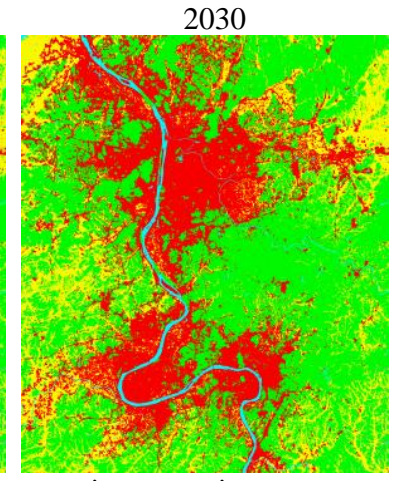

Constriction land water arable land other land use

Figure 4. Land use spatial optimization allocation in 2020 and 2030 under three different scenarios

\subsection{Scenarios of land use spatial optimization modelling}

Three different scenarios of urban land use were designed, which were urban integration development scenario, farmland and ecological protection scenario. The urban integration development scenario assumes that the future construction land area will be increased than that of natural increment. The farmland protection scenario assumes future permanent basic farmland protection zone will be increased. The ecological protection scenario assumes that areas along with the Xiangjiang River and its major branches, mountains and hills, and ecological landscape corridor between cities will be strictly restricted to use for construction.

Using the multi-agent land use spatial optimization model, we simulated the land use spatial optimization allocations in 2020 and 2030 under these three different scenarios. The modelling results are shown in Fig. 4.

The simulation results indicate that land use patterns and changes are different under different scenarios, which provide the basis for land use management and scientific decision-making of regional sustainable development.

\section{CONCLUSIONS}

A multi-agent land use spatial optimization model was proposed to support the optimized land use allocation practices. The model was first applied to the past land use data to test if it is capable of modelling land use allocations. It was further applied to simulate the future urban land use optimization allocation under three different scenarios for 2020 and 2030. The results show that land use patterns and changes are different in different scenarios. This kind of quantitative information about urban land use optimization allocation and urban expansions in future would be of great interest to urban planning, water and land resource management, and climate change research.

\section{ACKNOWLEDGMENTS}

This work has been funded by the National Science Foundation of China (No. 41171326, 40771198).

\section{REFERENCES}

An, L., 2012. Modeling human decisions in coupled human and natural systems: Review of agent-based models. Ecol. Modell. 229, pp. 25-36.

Chen, Y., Li, X., Liu, X., Liu, Y., 2010. An agent-based model for optimal land allocation (AgentLA) with a contiguity constraint. International Journal of Geographical Information Science. 24, pp. 1269-1288.

Haque A, Asami Y., 2014. Optimizing urban land use allocation for planners and real estate developers. Computers, Environment and Urban Systems, 37(4), pp. 57-69.

He, C., Okada, N., Zhang, Q., Shi, P., Zhang, J., 2006. Modeling urban expansion scenarios by coupling cellular automata model and system dynamic model in Beijing, China. Applied Geography. 26, pp. 323-345.

Jiang, L., Deng, X., Seto, K.C., 2013. The impact of urban expansion on agricultural land use intensity in China. Land Use Policy 35, pp. 33-39.

Li, X., Yeh, A.G.-O., 2002. Neural-network-based cellular automata for simulating multiple land use changes using GIS. International Journal of Geographical Information Science. 16, pp. 323-343.

Lin, G., Ho, S.P., 2003. China's land resources and land-use change: insights from the1996 land survey. Land Use Policy 20, pp. 87-107. 
Liu, J., Liu, M., Tian, H., Zhuang, D., Zhang, Z., Zhang, W., Tang, X., Deng, X., 2005. Spatial and temporal patterns of China's cropland during 1990-2000: an analysis based on Landsat TM data. Remote Sens. Environ. 98, pp. 442-456.

Liu, X., Li, X., Shi, X., Huang, K., Liu, Y., 2012. A multi-type ant colony optimization (MACO) method for optimal land use allocation in large areas. International Journal of Geographical Information Science. 26, pp. 1325-1343.

Liu, X., Ou, J., Li, X., Ai, B., 2013. Combining system dynamics and hybrid particle swarm optimization for land use allocation. Ecol. Modell. 257, pp. 11-24.

Seto, K.C., Fragkias, M., 2005. Quantifying spatiotemporal patterns of urban land-usechange in four cities of China with time series landscape metrics. Landsc. Ecol.20, pp. 871-888.

Verburg P E, Veldkamp A, Frescoa L O., 1999. Simulation of changes in the spatial pattern of land use in China. Applied Geography, 19, pp. 211-233.

Verburg P.H., Soepboer W., Veldkamp A., et al., 2002. Modeling the Spatial Dynamics of Regional Land Use: the CLUE-S Model. Environmental Management, 2002, 30(3), pp. 391-405. 